American Journal of Pharmaceutical Education 2020; 84 (8) Article 8021.

\title{
COMMENTARY
}

\section{Let External Stakeholders Be Your Guide to Curricular Revision}

\author{
Andrea L. Porter, PharmD, a,c Edward C. Portillo, PharmD, ${ }^{\text {a }}$ Casey E. Gallimore, PharmD, MS, ${ }^{a}$ \\ Joseph A. Zorek, PharmD, ${ }^{b}$ Susanne G. Barnett, PharmD ${ }^{a}$ \\ ${ }^{a}$ University of Wisconsin - Madison School of Pharmacy, Madison, Wisconsin \\ ${ }^{\mathrm{b}}$ The University of Texas Health Science Center at San Antonio, San Antonio, Texas \\ ${ }^{c}$ Editorial Board Member, American Journal of Pharmaceutical Education, Arlington, Virginia
}

Submitted February 12, 2020; accepted February 26, 2020; published August 2020.

\begin{abstract}
Schools and colleges of pharmacy undertake curriculum revisions for a variety of reasons ranging from the reactionary (eg, responding to changes in practice patterns, accreditation standards) to the proactive (eg, striving for innovation and excellence). Continuous quality improvement processes and published curriculum models, both described in this commentary, should be used to guide revision processes. Equally important is engaging the expertise of external stakeholders. While there may be challenges to incorporating external stakeholders in a curriculum revision process, their perspectives and knowledge can contribute to a more robust result, often in unexpectedly positive ways. Logic modeling is one mechanism to structure this approach, maximize the utility of external stakeholders, and strengthen the overall curriculum revision process. Regardless of the size of the revision, a good rule of thumb is to engage external stakeholders at the outset and to let their expertise be your guide.
\end{abstract}

Keywords: curriculum revision, continuous quality improvement, stakeholders, logic model

Effective pharmacy educators continuously monitor and revise courses and entire curricula at times to ensure graduates possess the requisite skills to meet societal needs and succeed as pharmacists. Because pharmacy practice is in a constant state of growth and evolution, the ability of schools and colleges of pharmacy to respond to emerging trends in healthcare is critical. When schools and colleges of pharmacy embark on a course or curriculum revision process, there are seemingly endless potential destinations, each with its own list of pros and cons. Further complicating matters, limited guidance exists, at least in terms of best practice, to light the way forward.

Course revisions should be rooted in continuous quality improvement (CQI) processes and evidencebased practices. ${ }^{1}$ Despite the absence of a specific Doctor of Pharmacy (PharmD) standard mandating CQI in course development and revision, accreditation guidance on this matter does exist. The following language, for example, is taken directly from the Accreditation Council for Pharmacy Education's (ACPE) Standards 2016: “it is expected that programs will exceed...required standards through initiatives designed to ensure continuous quality

Corresponding Author: Andrea L. Porter, University of Wisconsin - Madison School of Pharmacy, 777 Highland Ave., Madison, WI 53705. Tel: 608-890-0742. Email: andrea.porter@wisc.edu improvement." Additionally, the guidance document developed to accompany Standards 2016 includes "suggested strategies for quality improvement."3 This guidance shares successful and innovative approaches to enhance the quality of PharmD programs modeled off a CQI approach.

For every change at a pharmacy school, there are numerous potential stakeholders to consider. Internal stakeholders include students, faculty members, instructors, staff, and administrators. Externally, individuals with a vested interest in curricular revisions may include alumni, preceptors, other pharmacists not associated with the school, employers of pharmacy graduates, other healthcare professionals, and patients. External experts can assist with CQI processes by helping pharmacy schools stay up to date with rapidly changing areas of practice, especially within emerging fields. Another example is the impact of technological advances on pharmacy practice patterns, and hence the need to prepare graduates to leverage new technologies such as pharmacogenomic testing and point-of-care testing devices.

It can be tempting to revise curricula to incorporate the latest and greatest technologies, but this may be illadvised without external stakeholder input. Inspired by observed adoption of point-of-care testing devices in ambulatory settings, our team conducted a statewide survey of community pharmacies in Wisconsin to gauge uptake in this external stakeholder group. Preliminary 


\section{American Journal of Pharmaceutical Education 2020; 84 (8) Article 8021.}

results suggest that, at least in Wisconsin, large-scale curricular revisions to incorporate instruction on a wide range of point-of-care testing devices may be premature. Additionally, external stakeholders were integral to the development of a four-semester pharmacy skills course sequence at our institution. ${ }^{4}$ This commentary is a call to seek and use expertise outside the walls of our schools and colleges, like these examples, to inform robust curricular revisions.

While there is no singular recipe for designing curricula as a whole or engaging stakeholders specifically, curriculum models can provide valuable guidance on both. These models guide educators through the process of thinking about a curriculum in a purposeful way. ${ }^{5}$ Where numerous curriculum models exist, educators may find that core tenets of a particular model better support their desired goals. In this manner, several models support the concept of engaging external stakeholders in the instructional design process. Despite their age, these three models remain highly relevant to curriculum revision today, in particular as it relates to engaging external stakeholders.

Franklin Bobbitt, responsible for one of the oldest curriculum models, which dates back to the 1920 s, describes the value of society informing what is taught in schools. ${ }^{5}$ Bobbitt's model proposes work in two phases: discover the objectives for the curriculum and devise experiences for obtaining the objectives. His model emphasizes the importance of societal needs informing curricular objectives. In modern language, performing a needs assessment of stakeholders is a first step in identifying meaningful learning objectives.

Another influential and widely applied curriculum model comes from the combined work of Ralph Tyler and Hilda Taba. ${ }^{5}$ Tyler pioneered the Tyler Rationale, which proposes a series of questions to guide curricular work, two of which apply directly to engagement of stakeholders: What are the goals that schooling and the curriculum should serve? What should be included to meet those goals? ${ }^{6}$ In other words, Tyler encourages educators to purposely think about the scope of the curriculum as an early step. Taba later built off this concept by placing parameters around Tyler's Rationale to make it applicable at the classroom level and more generalizable across educators. ${ }^{5,7}$ Taba's model starts with a diagnosis of learner needs and uses this as the platform for formulating objectives. ${ }^{8}$ The curriculum does not begin with rigid, predetermined educational aims, but instead is fluid, based on collaboration and shared decision making among stakeholders. Educational strategies are determined through democratic guidance and partnerships formed by internal and external stakeholders in the area of study. ${ }^{7}$ In this way, the Taba model is grounded in a grass-roots approach to curriculum design.

Finally, Decker Walker proposed the Deliberate Model in 1971, which describes what he terms a deliberate platform. ${ }^{5}$ The deliberate platform is an understanding of the individual and collective beliefs about education, schools, and classrooms. This understanding forms the platform upon which curricular decisions are made. Applying Walker's Deliberate Model to pharmacy education, the perspectives of external stakeholders are one piece of a larger puzzle and should be considered in conjunction with internal stakeholders and accreditation standards. It is a balance between all these components that paints a diversified vision to inform curriculum and course development.

Few examples of using external stakeholders during course revisions were found in a review of the pharmacy education literature. Examples are difficult to find as they may often be a single component of a course revision and not the primary article focus. The few published articles that we identified included one that assessed pharmacy stakeholders' perspectives on pharmacy education and quality assurance in 15 Eastern Mediterranean countries, another study that reported on a survey of 162 practitioners that was conducted to inform the design of a pharmaceutical care laboratory course to ensure relevance to current and future pharmacy practice, and a third study that described findings from a pharmacist preceptor focus group conducted to inform the redesign of a sequence of skills-based courses. ${ }^{4,9,10}$

While the benefits of stakeholder engagement are well described within curriculum models, operationalizing a plan to identify key stakeholders can remain a challenge. One of the initial stages to identifying stakeholders include performing an analysis of the strengths, weaknesses, opportunities, and threats, also known as a SWOT analysis. ${ }^{11}$ This method was developed by the Stanford Research Institute in the 1960s for business and industry, but since then it has been applied to many different areas, including education. ${ }^{11}$ Strengths and weaknesses are identified through internal evaluations, while opportunities and threats requires expanding the assessment to include external factors. To thoroughly assess opportunities and threats, it is important to engage stakeholders, or those who may be involved or impacted by curricular revisions. When completing a SWOT analysis, it is necessary to engage stakeholders early in the process. ${ }^{11}$ Some have suggested changing the name to "TOWS analysis" to encourage organizations to engage external stakeholders first, before looking internally at the organization's strengths and weaknesses, because of the importance of stakeholder information in the change 


\section{American Journal of Pharmaceutical Education 2020; 84 (8) Article 8021.}

process. ${ }^{11}$ To most effectively identify external stakeholders, it is also important to know where your institution's pharmacy graduates are practicing.

Input provided by external stakeholders can lead to the strengthening of a course through incorporation of revisions not previously considered. While it is not appropriate or possible to engage all stakeholders through a given course revision process, it is important to consider and engage all relevant stakeholders. Consideration of already-existing contact points for external stakeholders within a school or college may facilitate connections to be made (eg, preceptor meetings, employer fairs, student interview days, newsletters, surveys, and webinars). If an in-person meeting is planned, food or a small monetary stipend may be used to encourage participation. Once connections are made, focus groups, interviews, and surveys are valuable tools to obtain feedback. When working with external stakeholders, it is important to engage in relationship building to ensure school engagement beyond the initial interaction.

Questions may arise throughout the curriculum revision process regarding how to identify valuable stakeholders, especially external ones. In the literature emphasizing business and project management, the challenge of stakeholder identification is well-researched and is considered a critical but difficult aspect of the project development process. ${ }^{12}$ Project management standards set by organizations such as the Project Management Institute often consider stakeholder identification based on level of influence and importance, with categorization titles such as project owner, sponsor, team-members, and project manager. ${ }^{13}$ Within healthcare, the challenges faced by researchers identifying stakeholders has led to modeling that illustrates stakeholder groups specific to patient-centered outcomes research, including the "Seven Ps" to categorize the following stakeholder groups: patients and the public, providers, purchasers, payers, policy makers, product makers, and principal investigators. ${ }^{14}$ To date, there is not a specific taxonomy, at least to our knowledge, that promotes stakeholder identification specific to curricular revision initiatives.

Logic modeling has been proposed as an effective approach to stakeholder engagement and curriculum designers should consider using it. ${ }^{15,16}$ A logic model demonstrates "shared relationships among the resources, activities, outputs, outcomes, and impact" of a particular program. ${ }^{17}$ The use of logic models is widespread and extends well beyond curriculum revision, including within the business and healthcare sectors. Logic models are used to promote a systematic approach to strategic planning, program development, and assessment. ${ }^{15}$ While there are numerous applications of logic modeling, we see a unique potential application within curriculum planning to identify and engage stakeholders, especially external ones.

A well-developed logic model provides a visual map of learning objectives and activities to evaluate the viability and quality of any PharmD program. A revision in one part of the curriculum will impact other parts of the curriculum, sometimes in unexpected ways. Leveraging the mapping component of a logic model to guide the curricular revision process can help uncover such impacts while also facilitating the identification of gaps or deficits that would benefit from the strategic selection and engagement of specific external stakeholders. Despite being a time-consuming process, mapping courses and curriculum using the logic model approach can assist in providing students with high-quality learning experiences. ${ }^{4}$ Mapping results provide a lens for faculty members to interpret and consider input from external stakeholders during the course revision process.

One beneficial aspect of the logic modeling process involves identification of a situation statement, which requires educators to critically consider the following questions: What is the problem or issue being addressed with the new curriculum? For whom does this problem exist? Who has a stake in the problem? ${ }^{18}$ Considering these questions, among others, allows educators to quickly determine key stakeholders to engage with early in the curriculum design process. Stakeholders can then collaborate with curriculum planners to further explore the important questions, ie, why do the problems identified exist, and how do these problems impact individuals, groups, and society as a whole? The application of logic modeling equips curriculum planners with the necessary questions to engage the most appropriate external stakeholders to clearly identify curricular goals, and, throughout the process, consider the short-, medium-, and long-term goals of the new curriculum.

Obtaining input from stakeholders to inform the continuous quality improvement process allows for comprehensive data to be considered, which provides justification for evidence-based course and curriculum revisions. The fact that this is encouraged by ACPE provides a good reason to do so. More compelling, however, is the fact that curriculum models and evidence dating back over a century points towards the value of this approach. Engaging external stakeholders systematically, whether through a SWOT analysis, or as one component of a logic model, as suggested, can lead to a strategically orchestrated curriculum needed to produce pharmacy graduates capable of meeting societal needs. When it comes to curricular revision, let external stakeholders be your guide. 


\section{American Journal of Pharmaceutical Education 2020; 84 (8) Article 8021.}

\section{REFERENCES}

1. Barzansky B, Hunt D, Moineau G, et al. Continuous quality improvement in an accreditation system for undergraduate medical education: benefits and challenges. Med Teach.

2015;37(11):1032-1038.

2. Accreditation Council for Pharmacy Education. Accreditation Standards and Guidelines for the Professional Program in Pharmacy Leading to the Doctor of Pharmacy Degree (Standards 2016).

Accessed December 29, 2019. https://www.acpe-accredit.org/pdf/ Standards2016FINAL.pdf.

3. Accreditation Council for Pharmacy Education. Guidance for the Accreditation Standards and Key Elements for the Professional Program in Pharmacy Leading to the Doctor of Pharmacy Degree (Guidance for Standards 2016). Accessed January 4, 2020.

4. Gallimore CE, Porter AL, Barnett SG. Development and application of a stepwise assessment process for rational redesign of sequential skills-based courses. Am J Pharm Educ. 2016;80(8):136. 5. Hewitt TW. Understanding and Shaping Curriculum: What We Teach and Why. Thousand Oaks, Calif.: Sage Publications; 2006. 6. Tyler RW, Hlebowitsh PS. Basic Principles of Curriculum and Instruction. Chicago; London: The University of Chicago Press; 2013.

7. Laanemets $\mathrm{U}$, Katrin $\mathrm{K}$. The Taba-Tyler Rationales. JAAACS. 2013;9:1-12.

8. Taba H. Curriculum Development; Theory and Practice. New York: Harcourt; 1962.

9. Bajis D, Moles R, Hosp D, Chaar B. Stakeholders' perspectives on quality assurance of pharmacy education in the eastern mediterranean region. Am J Pharm Educ. 2018;82(10):6482.
10. Chereson R, Bilger R, Mohr S, Wuller C. Design of a pharmaceutical care laboratory: a survey of practitioners. Am J Pharm Educ. 2005;69(1).

11. Gomer J, Hille J. An Essential Guide to SWOT Analysis. Accessed December 2, 2019. http://mci.ei.columbia.edu/files/2012/ 12/An-Essential-Guide-to-SWOT-Analysis.pdf

12. Rahman M, Ali M, Malik N, Ahmad M, Asmi F. Essential skills for project stakeholders identification: sustainability perspective. IJBSR. 2017;7(8):43-55.

13. Smith L. Stakeholder analysis: a pivotal practice of successful projects. Paper presented at: Project Management Institute Annual Seminars \& Symposium, 2000; Houston, TX. Newtown Square, PA: Project Management Institute.

14. Concannon TW, Meissner P, Grunbaum JA, et al. A new taxonomy for stakeholder engagement in patient-centered outcomes research. J Gen Intern Med. 2012;27(8):985-991.

15. W.K. Kellogg Foundation. Using Logic Models to Bring Together Planning, Evaluation, and Action: Logic Model Development Guide. W.K. Kellogg Foundation. Accessed January 4, 2020. https://www.bttop.org/sites/default/files/public/W.K.\% 20Kellogg\%20LogicModel.pdf

16. Loberti A, Dewsbury B. Using a logic model to direct backward design of curriculum. J Microbiol Biol Educ. 2018;19(3):1-4.

17. Centers for Disease Control and Prevention. Logic Models. Accessed January 4, 2020. https://www.cdc.gov/eval/logicmodels/index.htm 18. University of Wisconsin-Extension. Enhancing Program Performance with Logic Models. University of Wisconsin-Extension. Accessed January 4, 2020. https://fyi.extension.wisc.edu/ programdevelopment/files/2016/03/lmcourseall.pdf 